Short Communication

\title{
Study on the Synergistic Effect of Iodide Ion with the Extract of Artemisia Halodendron on the Corrosion Inhibition
}

\author{
Hui Cang, Zhe Tang, Hengye Li, Lei Li, Jingling Shao, Huaihong Zhang * \\ College of Chemistry and Chemical Engineering, Yancheng Institute of Technology, Yancheng \\ 224051, China \\ *E-mail: Canghui_ycit@126.com, zhh5817@163.com
}

doi: $10.20964 / 2017.11 .24$

Received: 21 June 2017 / Accepted: 2 September 2017 / Published: 12 October 2017

\begin{abstract}
The synergistic inhibition effect of iodide ion with the extracts of Artemisia Halodendron was studied by electrochemical potentiodynamic polarization methods. It was found that the inhibition efficiency increased with increasing the iodide ion concentration when fixed the concentration of the extract. But increased first and decreased then with increasing concentration of the extract when fixed the iodide ion concentration. The synergism parameters were evaluated from the inhibition efficiency values. SEM and EDX study confirmed the corrosion inhibition of the extract and iodide ion on the mild steel surface in $\mathrm{HCl}$ solution.
\end{abstract}

Keywords: Plant extract, Corrosion, Green inhibitor, Acid solution

\section{$\underline{\text { FULL TEXT }}$}

(C) 2017 The Authors. Published by ESG (www.electrochemsci.org). This article is an open access article distributed under the terms and conditions of the Creative Commons Attribution license (http://creativecommons.org/licenses/by/4.0/). 